\title{
A HISTÓRIA DA ELABORAÇÃO DO BGB ALEMÃO
}

\author{
Peter Walter Ashton ${ }^{1}$
}

Quando, em 1814, o Prof. Anton Friedrich Justus Thibaut, da Faculdade de Direito da Universidade de Heidelber,g publicou o seu livro intitulado Da Necessidade de um Direito Civil Geral para a Alemanha mostrou-se otimista, pois previa a elaboração de tal código num período de dois a quatro anos. Citou como exemplo o Code Civil francês. No entanto, o momento político na Alemanha não era propício a tal empreendimento de envergadura. Quando, finalmente, a unificação da Alemanha em 1871 (Versailles) criou as condições básicas para o início da unificação também do direito civil alemão, demoraria mais 22 anos até o término dos trabalhos das sucessivas comissões. Além disso, Thibaut envolveu-se em famosa discussão jurídica (1815) com outro jurista alemão, ainda mais proeminente do que ele, a saber: Friedrich Carl Von Savigny, que até os dias de hoje ainda é considerado o jurista alemão mais importante. Savigny é considerado o fundador da Escola Histórica do Direito contra a "Escola do Direito Natural”. O jurista baseava boa parte de sua teoria nos trabalhos pioneiros do Professor Gustav Hugo da Universidade de Göttingen, mas que por tradição e costume, embora inovador, ainda era influenciado pela Escola do Direito Natural.

Savigny, no entanto, revolucionário no seu pensamento, abandonou totalmente a Escola do Direito Natural dos séculos XVII e XVIII e seus ensinamentos, afirmando (simplificando)

1 Professor titular aposentado nas Faculdades de Direito da Universidade Federal do Rio Grande do Sul e da Pontifícia Universidade Católica do Rio Grande do Sul. Mestre e doutor em Direito. Livre-docente em Direito Comercial. Advogado Militante e consultor jurídico. 
que o Direito, as normas jurídicas não devem ser buscadas na natureza ou derivadas da razão do homem, mas que o Direito é um produto histórico, um produto do Espírito do Povo. De acordo com Savigny e sua Escola Histórica do Direito, a tarefa do jurista não era mais raciocinar sobre como construir e elaborar uma ordem jurídica adequada para os homens, mas simplesmente coletar a matéria jurídica produzida pelo Espírito do Povo e, após, ordenar e sistematizar a matéria jurídica assim coletada. Era exatamente isso que o professor Gustav Hugo tinha ensinado na sua cadeira em Göttingen. Savigny pontificava que, primeiro: o direito, as normas já existentes, o direito positivo encontrado, deveria ser reconhecido e fixado e após completamente coletado, catalogado e finalmente sistematizado.

Ele afirmou e escreveu exatamente isso no artigo de introdução e apresentação do primeiro volume da Revista Jurídica Histórica no ano de 1815 página 06.

O entendimento fundamental da Escola Histórica do Direito (Alemã) era, até certo ponto, assim como no Direito Natural, de natureza científica naturalística, mas não era mais matemático, geométrico e baseado na física, era, ao contrário, internamente biológico e evolucionista.

Dessarte a Escola Histórica (alemã) do Direito, integrava-se às ideias biológicas e orgânicas da Teoria Eco- nômica Burguesa dos Fisiocratas franceses e ao legado do inglês Adam Smith. O imaginário do organismo da Sociedade representa a autonomia da sociedade frente ao regramento estatal (UWE WESEL: JURISTISCHE WELTKUNDE. SurKamp, 1993, p. 87). Um organismo funciona de forma autônoma, independente, orgânica. Intervenções de parte do Estado são deletérias. Prejudicam. Já em 1758 François Quesnay, no seu "Tableau Économique”, comparava a circulação dos bens, produtos e valores da economia de um país como uma espécie de circulação sanguínea que se estabiliza e equilibra autonomamente. Representava o laissez-faire burguês contra o direcionamento mercantilístico da economia, contra construções matemáticas, geométricas e mecânicas que correspondem ao planejamento estatal e direcionamento estatal da economia. Arbítrio estatal, dizia Savigny. Contra isso deve agir a sociedade como um organismo biológico, vinculado a um agir recôndito e autônomo do Espírito do Povo, que representa autenticamente a sociedade burguesa. É ali, na sociedade, e não no Estado que é formulado o Novo Direito baseado na Ciência Burguesa representada pela Escola Histórica do Direito e pelo seu Direito das Pandectas.

Portanto, o autêntico Direito da sociedade burguesa não deve ser um produto de leis estatais, como ocorre no Direito Natural. 
Esse era o cerne da briga entre Thibaut e Savigny, e quem levou a melhor nessa discussão foi Savigny, pois a sua estatura social e acadêmica, como jurista educador, era imbatível.

Savigny foi um dos fundadores, juntamente com Alexander Von Humboldt, da Universidade de Berlim, em 1813. Foi reitor da universidade. Professor do Príncipe herdeiro o posterior rei Frederico Guilherme IV da Prússia. Foi Conselheiro de Estado da Prússia, Ministro da Justiça da Prússia de 1842 a 1848 e, já na época, era considerado a autoridade máxima da Ciência Jurídica Alemã. Passado mais de meio século desde essa briga, fundou-se em 1871 o Império Alemão. Tal acontecimento propiciou a base para a elaboração de uma legislação nacional alemã. Em 1873, o Reichstag (Parlamento Alemão) foi autorizado a elaborar um Código Civil Nacional.

Em 1874, começaram as primeiras sessões de trabalho e elaboração, mas apenas em 1896, 22 anos depois, o labor estava terminado. O Código Civil Alemão entrou em vigor em 01 de janeiro de 1900, tal qual como ocorreu com o Code Civil francês de 1807. O BGB foi elaborado durante uma época de relativa tranquilidade. Com certa razão, foi afirmado que o BGB foi lançado no último momento adequado. Dez anos depois, pouco antes da Primeira Guerra Mundial, a sua entrada em vigor não mais teria sido possível.
A primeira comissão preparatória composta de 11 juristas iniciou seus trabalhos ainda em 1874. Bernhard Windscheid era um dos onze. Windscheid assumiu no mesmo ano (1874) a sua cátedra de Direito Romano na Universidade de Leipzig e, à época, o seu Manual Direito das Pandektas dominava a Ciência e Prática jurídicas na Alemanha. A "comissão dos onze” trabalhou 13 anos antes de portas fechadas e, em 1887, apresentou a sua primeira versão de um BGB. Essa primeira versão estava tão impregnada das ideias de Windscheid e do seu Manual que a versão final, bastante modificada, ainda era considerada um manual do direito das pandectas de Windscheid, embora vasado em artigos e parágrafos.

O projeto do BGB veio acompanhado de 5 grossos volumes com fundamentações e explicações. O total somava mais de 4.000 páginas de letra impressa pequena.

Imediatamente, em 1887, começaram fortes críticas ao projeto. Os juristas germanistas, especialmente 0 professor Otto Von Gierke, afirmavam que o projeto não levava suficientemente em conta o direito alemão. Os romanistas adeptos e seguidores do direito romano entendiam que os raciocínios e ideais do direito romano tinham sido pouco utilizados.

O socialista e teórico Anton Menger, defensor de um estado dos trabalhadores de natureza popular, mani- 
festou-se contra o projeto em nome do socialismo e das classes sociais sem propriedade. Já outros criticavam que a primeira comissão, a dos onze, era composta exclusivamente de juristas. Também o linguajar, a redação, o vocabulário do projeto era considerado rebuscado e incompreensível. Em decorrência dessa avalanche de críticas, nomeou-se uma segunda comissão no ano de 1890 tendo Gottlieb Planck como presidente. Participaram da comissão pessoas não juristas e um banqueiro. A comissão desenvolveu os seus trabalhos e estudos publicamente, a portas abertas, e não a portas fechadas como a comissão anterior. Apresentou um segundo projeto de código civil no ano de 1895 que tinha a característica de ser mais inclinado ao direito germânico e menos ao direito romano. Quanto ao vernáculo e vocabulário, continuava ainda bastante abstrato e bem mais complicado de entender que o Code Civil francês. Esse segundo projeto é amplamente similar à versão final do Código BGB. O BGB compreende 5 livros: a parte geral, o direito das obrigações, o direito das coisas, o direito de família e o direito das sucessões. Aliás, nisso manteve a tradição do Corpus Júris Civilis do Imperador Justiniano.

A parte geral contém todas as regras fundamentais que regulam as relações jurídicas de direito privado, assim, por exemplo: normas sobre capacidade jurídica, habilitação para realização de negócios, declarações de vontade, contratos de representação etc. O direito obrigacional regula as relações jurídicas entre credores e devedores; contém uma parte geral específica e normas/regras especiais para relações obrigacionais na área de compra e venda, locação, empréstimo etc. O direito das coisas trata dos direitos relativamente às coisas como, por exemplo, propriedade e posse. $\mathrm{O}$ direito de família regulamenta as relações pessoais e de natureza patrimonial entre marido e mulher, ascendentes, filhos e parentes, bem como a tutela e a curatela. Finalmente, o direito das sucessões regulamenta a transmissão do patrimônio do "de cujus” em caso de morte.

O debate do projeto no Parlamento Alemão não foi muito intenso, o que surpreende quando se considera a enorme importância da matéria contida no projeto. Apenas um ponto, um aspecto do projeto, ou seja, quanto à responsabilidade em caso de danos causados pela caça ilegal (revogado hoje em dia), que era regulada no parágrafo 835 do $\mathrm{BGB}$, causou um debate acalorado, do qual participaram nada menos do que 30 deputados. $\mathrm{O}$ ponto do debate era a rigor ridículo, pois tratava da exclusão dessa responsabilidade no caso da caça ilegal de coelhos. O resultado do intenso debate foi no sentido de excluir de qualquer responsabilidade por danos 
a caça ilegal de coelhos, que assim foram excluídos da incidência do §835 do BGB. Permaneceram sujeitos ao $\S 835$ porcos selvagens, veados em geral e faisões. Na hora da votação final do projeto, 222 deputados votaram pela aprovação e 48 contra em data de 18/08/1896.

Nessa mesma data, a lei do BGB foi sancionada pelo Imperador Guilherme II. Acompanhado de uma lei de introdução e de uma nova versão do Código Comercial alemão, o BGB entrou em vigor em 01 de janeiro de 1900.

O BGB espelha as relações e condições sociais, políticas e intelectuais vigentes na Alemanha e na Europa no século XIX. Era impregnado com o Leitbild do empresariado liberal da época. As classes sem propriedades nem posses eram fortemente ignoradas, havendo poucas normas no BGB que as protegessem. Normas que garantissem uma compensação social eram esporádicas. No entanto, por meio das cláusulas gerais, especialmente a da boa-fé (TREU UND GLAUBEN), BGB 242, tais elementos de compensação social por força da prática do direito conseguiram penetrar na sistemática jurídica. Similarmente ao Code Civil Francês de 1807 , o contrato e a propriedade eram a base do BGB.

O BGB definiu propriedade como sendo o "direito de utilizar a coisa livremente e de excluir terceiros de qualquer interferência, o que hoje em dia ainda consta no §903 do BGB”.

Essa definição clássica do livre-arbítrio do proprietário sobre a coisa já era considerada em 1900, em vista da posição na época do direito público uma posição absurda.

Traços conservadores, patriarcais e autoritários caracterizavam o BGB, especialmente no direito de família.

A característica positivista do BGB impelia o aplicador das suas normas a esforçar-se a regular todos e quaisquer fatos e relações da vida. Nesse aspecto, os operadores da aplicação das normas do BGB não seguiram o caminho da casuística, mas levaram o uso e a aplicação das normas do BGB a um alto nível técnico-legal. O preço que a Alemanha pagou por esse comportamento jurídico-tecnicista era uma falta de compreensão de parte do público e das partes, bem como uma grave deficiência no relacionamento com o povo. $\mathrm{O}$ BGB nunca se tornou verdadeiramente popular. Passou a ser um instrumento de precisão na mão de juristas devidamente preparados para aplicá-lo. Com essas características, passou a ser modelo para muitos países. O BGB influenciou o Código Civil Suíço, que entrou em vigor em 1912. Todavia, o Código Civil Suíço tem uma linguagem, vocabulário e redação muito mais simples que o BGB. Os códigos civis da Turquia, do Japão e do Brasil (Clóvis Bevilacqua, 1916) também foram influenciados pelo BGB alemão. 
A intenção original de reunir no Código todo o direito privado com exceção do direito comercial não foi concretizada. Amplas áreas do direito privado continuaram com legislação independente e própria, principalmente na área dos direitos estaduais.

O regime nazista começou a retalhar o BGB em blocos de normas autônomas, a fim de substituí-lo ao final por um novo código do povo alemão, mas a empreitada com a destruição do regime nazista soçobrou. A evolução e tendência moderna no Direito Civil e privado alemão é no sentido de eliminar leis especiais e de reformar o BGB continuamente com novas alterações.

Observação: para a elaboração deste artigo foram consultados vários autores alemães, especialmente UWE WESEL. 